\title{
Montgomery, informed consent and causation of harm: lessons from Australia or a uniquely English approach to patient autonomy?
}

\author{
Malcolm K Smith, Tracey Carver
}

Australian Centre for Health Law Research, School of Law, Queensland University of Technology, Brisbane, Queensland, Australia

\section{Correspondence to}

Dr Malcolm K Smith, Australian Centre for Health Law Research, School of Law, Queensland University of Technology, Brisbane, Queensland 4001 Australia; mk.smith@qut.edu.au

Received 17 March 2017 Revised 16 January 2018 Accepted 6 February 2018 Published Online First 23 March 2018

\begin{abstract}
The UK Supreme Court in Montgomery v Lanarkshire Health Board adopts an approach to information disclosure in connection with clinical treatment that moves away from medical paternalism towards a more patient-centred approach. In doing so, it reinforces the protection afforded to informed consent and autonomous patient decision making under the law of negligence. However, some commentators have expressed a concern that the widening of the healthcare providers' duty of disclosure may provide impetus, in future cases, for courts to adopt a more rigorous approach to the application of causation principles. The aim would be to limit liability but, in turn, it would also limit autonomy protection. Such a restrictive approach has recently been adopted in Australia as a result of the High Court decision in Wallace v Kam. This paper considers whether such an approach is likely under English negligence law and discusses case law from both jurisdictions in order to provide a point of comparison from which to scope the post-Montgomery future.
\end{abstract}

\section{INTRODUCTION}

In Montgomery $v$ Lanarkshire Health Board, ${ }^{1}$ the UK Supreme Court clarified that the duty of care in negligence regulating the provision of informed consent to medical treatment requires information to be disclosed if it would be significant to a particular patient's decision making. The case is important, most notably because the test relevant to the standard of information disclosure was previously regarded as paternalistic. ${ }^{2}$ Following the House of Lords decision in Sidaway $v$ The Royal Bethlem Hospital, ${ }^{3}$ the law appeared to focus not on the significance of information from the patient's perspective but on whether peer professional opinion would regard the disclosure of particular treatment risks to be appropriate. ${ }^{4}$ The question of whether professional opinion should dictate the disclosure of information in this way had however remained in the background ${ }^{5}$ with subsequent jurisprudence $^{6}$ and professional guidelines ${ }^{7}$ supporting a more patient-centred interpretation.

In the early 1990s, the Australian High Court in Rogers $v$ Whitaker $^{8}$ had explicitly rejected the decisiveness of professional opinion in determining information disclosure and had instead established a duty to provide advice regarding 'material' risks of surgery and other medical interventions (pp 483, 490). ${ }^{8}$ Following Montgomery, the English law of negligence applied to a healthcare provider's duty to disclose now also reflects this position. ${ }^{9}$ It requires taking 'reasonable care to ensure that the patient is aware of any material risks involved in any recommended treatment, and of any reasonable alternative or variant treatments' (para 87). ${ }^{1}$ For the purpose of identifying material risks, Montgomery explicitly adopts the same objective and subjective limbs of the test formulated in Rogers:

\footnotetext{
The test of materiality is whether, in the circumstances of the particular case, a reasonable person in the patient's position would be likely to attach significance to the risk, or the doctor is or should be reasonably aware that the particular patient would be likely to attach significance to it (emphasis added) (para 87). ${ }^{1}$
}

In departing from Sidaway, the current approach under English negligence law therefore places renewed emphasis on self-determination or the need for the law to respect and facilitate autonomous patient decision making about medical procedures due to the obvious impact of such decisions on a patient's own life and body. ${ }^{10} 11$ It does this by enabling patients, when undergoing medical procedures, to make meaningful choices through requiring the provision of information about treatment risks, options and side effects relevant to them. As a consequence, the importance of tailoring advice to a patient's 'needs, concerns and circumstances' is now manifest (para 73). ${ }^{1}$

The impact of this approach will no doubt be monitored closely by professionals and National Health Service Resolution. Indeed, Montgomery has been criticised for creating unrealistic disclosure obligations and exposing healthcare professionals to increased civil liability. ${ }^{12}$ However, while the Australian decision of Rogers generated similar criticism, ${ }^{13}$ "the "floodgates" of cases alleging a negligent failure to inform' have not opened. ${ }^{14}$ Recent data on medical indemnity claims in Australia, not all of which proceeded to litigation or settlement, indicates that the proportion of new claims relating to consent or failure to warn decreased from $2.4 \%$ to $1 \%$ between 2008 and $2013 .{ }^{15}$ In England, it is possible that Montgomery's notoriety may, in the short term, make such claims de rigueur, but given that professional guidelines ${ }^{7}$ already emphasise the more patient-centred approach mandated by the UK Supreme Court, ${ }^{2510}$ commentary has equally questioned the extent to which claims will be increased
J Med Ethics

2018:44:384-388 
by Montgomery's wider disclosure requirements. ${ }^{2516}$ Greater participation in decision making may also reduce a patient's desire for recrimination (para 93). ${ }^{1}$

Despite this, it remains that, post-Montgomery, 'responsibility for determining the nature and extent' of patient rights to autonomy or informed decision making, now 'rests with the courts, not with the medical profession' (para 83). ${ }^{1}$ Consequently, some commentators are curious as to whether causation principles might be used in the future as a control mechanism to, in fact, limit the liability of English healthcare providers in this context. ${ }^{25}$ In this paper, we consider whether this is likely. In doing so, we discuss case law that has emerged in Australia and England since Rogers, most notably Wallace $v \mathrm{Kam}^{17}$ and Chester $v$ Afshar,${ }^{18}$ in order to provide a point of comparison in terms of scoping the future direction that English negligence law might take following the Montgomery decision.

\section{THE DECISION IN MONTGOMERY}

The Supreme Court appeal in Montgomery centred on the liability of an obstetrician who failed to advise her patient about the risk of shoulder dystocia inherent in child birth. In Mrs Montgomery's circumstances, complications arose during labour and shoulder dystocia occurred. As a result, her baby was diagnosed with a brachial plexus injury causing Erb's palsy and cerebral palsy due to oxygen deprivation. Mrs Montgomery commenced a claim on behalf of her child seeking damages for his injuries.

As a diabetic and woman of small stature, there was an increased risk of this type of dystocia during Mrs Montgomery's labour. Shoulder dystocia is a major obstetric complication that results when, during delivery, the baby's shoulders cannot descend through the mother's pelvis. The risk in the case of a pregnant woman with diabetes, where the fetus is likely to be larger, was estimated to be $9 \%-10 \%$ (para 13). ${ }^{1}$ Of those cases, the risk to the child of brachial plexus injury was $1 / 500$, while the risk of such babies also sustaining more serious injury, such as cerebral palsy or death, was $<1 / 25000$ (paras 229,11 ). ${ }^{19}$ In most instances, no injury occurs.

The background to proceedings leading to the Supreme Court decision has been examined and critiqued elsewhere. ${ }^{25}{ }^{12}$ It is relevant, however, that the risk considered by the lower courts for the purpose of deciding principally whether a breach of the duty of disclosure had occurred was not the $9 \%-10 \%$ chance of shoulder dystocia but the risk of the adverse outcome should dystocia occur. ${ }^{\mathrm{i}}$ This conclusion flowed from an exception

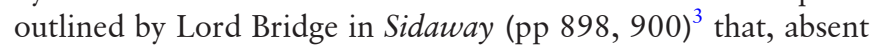
a request for information, peer professional opinion would not dictate a risk's significance, and a duty to disclose it would arise, if it was 'a substantial risk of grave adverse consequences'. As such, although grave, both the Outer and Inner Houses of the Court of Session determined that in Montgomery, the risk of physical injury to the child was insufficiently probable to warrant disclosure (paras 233-234, 29-30). ${ }^{19}$

Unlike the lower courts, the Supreme Court was not bound by Sidaway. It therefore focused on the obstetrician's failure to advise of the risk, not of injury to the child, but of the dystocia and the possibility of alternative delivery by caesarean section (para 2). ${ }^{1}$ In reformulating the test for providing advice about

\footnotetext{
${ }^{\mathrm{i}}$ It was recognised that the nature of the disclosed risk might differ had Ms Montgomery's secondary claim, that she had expressly questioned her obstetrician about the risks of vaginal delivery, been accepted (paras $238,31)^{19}$
}

treatment, and finding the obstetrician negligent (paras 94-105, 109-113), ${ }^{1}$ the Court confirmed that whether a risk is sufficiently significant to require disclosure 'cannot be reduced to percentages' (para 89), ${ }^{1}$ but must reflect the characteristics of the case and the patient. Accordingly, in terms of the test of materiality, the heightened risk of shoulder dystocia in Mrs Montgomery's circumstances was of such likelihood (at 9\%-10\%), and potential gravity to mother ii and child, that, objectively, it was a risk that a reasonable patient in those circumstances would find significant. Turning to the test's subjective limb, given that Mrs Montgomery had expressed concern about her ability to deliver vaginally (paras 17,73$),{ }^{1}$ it was also a risk that her obstetrician knew she would attach significance to. By comparison, the risks of caesarean section were extremely small.

The Supreme Court also accepted that had the required warning of the risk been given, Mrs Montgomery would have elected to undergo a caesarean section and her baby would have been born unharmed (paras 103-104). ${ }^{1}$ This was confirmed by the obstetrician, who gave evidence that if the risk of shoulder dystocia were mentioned, every diabetic mother would request a caesarean section. Indeed, because of this, she did not discuss the risk with Mrs Montgomery, being of the opinion that it was 'not in the maternal interests of women to have caesarean sections' (para 13). ${ }^{1}$ In reaching their decision in favour of liability, the Supreme Court therefore emphasised that it is the patient, not the professional, who should determine whether a risk should be borne (paras 81, 114-115). ${ }^{1}$

In the discussion that follows, we examine Australian case law relevant to determining the scope and purpose of the duty to disclose material risks, and in particular the issue of causation, and contrast this with English negligence law. Ultimately, we seek to demonstrate that the duty's underlying purpose, in promoting patient decision-making autonomy, appears much stronger in England than in Australia. For this reason, although causation principles have been used as a control mechanism to rein in the liability of health providers for non-disclosure of material risks in Australia ${ }^{17}$ we question the extent to which this will occur in English decisions post-Montgomery.

\section{THE SIGNIFICANCE OF CAUSATION PRINCIPLES}

Causation is often the most difficult element of the negligence action to satisfy in cases concerning a failure to disclose material risks. It has two key components. The first is 'factual causation', which requires that the harm or damage suffered by the claimant be linked, as a matter of fact, to a breach of duty. To establish this, the burden is on the patient to show that had a material risk been disclosed, a decision would have been made to refuse the procedure completely or postpone it to some future time when it would then be more probable than not that the harm would have been avoided. ${ }^{17-20}$ The precise identification of the risk is therefore central to this inquiry. In Montgomery, the Supreme Court ultimately concluded that, factually, the harm would not have occurred 'but-for' the obstetrician's breach (paras 103-105). ${ }^{1}$ This was because, had the risk of dystocia been known, the birth would have proceeded via caesarean section and not vaginally. As discussed further below, the lower courts however, in focusing on the likely reaction had Ms Montgomery been told only of the different and lesser risk of serious harm to her child, found factual causation unproved (paras 264-267, 43-48). ${ }^{19}$

\footnotetext{
ii Maternal risks included postpartum haemorrhage (11\% risk), perineal tears $(3.8 \%$ risk) and the potential need for a symphysiotomy.
} 
Nevertheless, even where factual causation is established, it is also necessary that the harm claimed be of a type regarded not too remote in law. This component is referred to as 'legal causation' or 'scope of liability', and can require an assessment of any policy-based factors that might influence a court to determine whether a healthcare provider should be held liable. Since a defendant's liability should not extend to harm occurring outside the scope of their legal obligations, such factors can include the purpose of a duty of care owed. ${ }^{21}$ Some commentators have identified this aspect of the law as a potential basis for limiting liability in future non-disclosure cases. ${ }^{25}$ Such an approach is exemplified by the Australian case of Wallace $v$ Kam. ${ }^{17}$

\section{CAUSATION AS A CONTROL MECHANISM The Australian decision of Wallace $v$ Kam}

In Wallace, a neurosurgeon failed to disclose two distinct risks inherent in a lumbar fusion procedure. The first was the possibility of bilateral femoral neurapraxia or temporary local nerve damage to the anterior femoral region of the leg. The second concerned a more serious chance of permanent and catastrophic paralysis from spinal nerve damage at the operation site (estimated to occur in 1 in 20 procedures). Although there was no negligence in the performance of the procedure itself, the patient developed postsurgical neurapraxia and commenced a negligence action based on the surgeon's failure to disclose both risks. Notably, because they were material, the surgeon had a duty to provide information about each risk as part of one comprehensive body of disclosure (pp 380, 387). ${ }^{17}$ In terms of causation, however, the case was unique in that the patient conceded that if warned of the risk of neurapraxia alone, he would have proceeded with the surgery at that time. Significantly, the patient argued that if also warned of the more serious risk of spinal nerve damage, he would have refused the operation completely thereby avoiding the neurapraxia (p 379). ${ }^{17}$

It was assumed, for the purpose of appeal, that 'factual causation' could be established in that had both risks been known the patient would have declined surgery ( $\mathrm{p} 387$ ). ${ }^{17}$ However, the High Court refused to extend liability to the surgeon on the basis of 'legal causation'. It held that it is not always appropriate for liability to extend to a healthcare professional for a failure to disclose material risks, simply because factual causation can be established ( $\mathrm{p}$ 387) ${ }^{17}$ Instead, the Court emphasised that the imposition of liability must be consistent with the purpose or policy underpinning the duty. According to the Australian High Court, the purpose under Australian negligence law is to protect patients from 'the occurrence of physical injury the risk of which is unacceptable to the patient' (emphasis added) (p 390). ${ }^{17}$ It is not, more broadly, to protect a patient's right to choose, nor is it to protect patients from mere exposure to undisclosed risks (p 381). ${ }^{17}$ Fundamentally then, the question of whether liability should be imposed in Wallace turned on the rationale for the duty of disclosure and the patient's willingness to run the particular risk of harm that occurred. The patient had admitted that if warned solely of neurapraxia, they would have continued with the procedure. Hence, this risk, unlike the potential for paralysis, was not unacceptable to the patient and the negligence claim failed.

Despite the congruence in Wallace between the injury suffered and a non-disclosed risk of harm (the neurapraxia), legal causation was used as a control mechanism to avoid imposing liability on the surgeon in a manner that suggested a narrowing of the legal duty's purpose, or scope of liability, when compared with earlier cases. For example, the duty in Rogers had previously been described as so 'conducive to respect for the integrity of the patient and better health care' that if not complied with 'it should occasion no surprise that legal consequences follow' (pp 272, 277). ${ }^{20}$ This arguably supported a liability finding once the non-provision of material information was shown. It should also be noted that Wallace was not a case where the patient was claiming compensation for the mere infringement of his autonomy or right to choose; physical injury was sustained. As proof of damage is essential to negligence, the direct protection of autonomy rights or informed decision making has traditionally fallen outside the action's purview such that a patient's unknowing exposure to risk alone is not actionable (p 240). ${ }^{20}$ Instead, such rights remain to be promoted only indirectly on the causation of actual tangible harm. Wallace appears to reinforce this position for Australia. Still, even the incidental protection of decision-making autonomy appears weakened by a rule that denies liability, despite the non-disclosure of multiple risks of injury, on the grounds that although it would have been avoided had all information been known, the only risk of harm that occurred was one which, in isolation, the patient was willing to accept.

\section{The duty to disclose under English negligence law: wider in scope and purpose?}

In contrast to Wallace, English case law seems to attribute a wider scope and purpose to the duty to disclose material risks. While being slower to adopt a patient-focused approach in framing the duty itself, the role of autonomy in underpinning the practitioner's obligation has been more pivotal in English negligence law since the House of Lords' 2005 decision in Chester $v$ Afshar. ${ }^{18}$

Chester concerned a surgeon's failure to warn of a $1 \%-2 \%$ risk of neurological injury that had occurred following spinal surgery. The key issue centred on causation. Although the patient was uncertain whether she would have refused the procedure had she known of the risk, she argued that she would have at least postponed it and sought alternative advice. 'Factual causation',iii was therefore established. Because the risk was so small, it was more probable than not that it would not have occurred had the surgery happened at a later time. However, in Chester, the injury was also 'as liable to occur whenever the surgery was performed and whoever performed it' ( $p$ 141). ${ }^{18}$ Consequently, as the surgeon's conduct had not increased the patient's risk exposure or exposed them to an unacceptable risk, it had not really caused anything. Due to this, the Court felt obliged to consider whether the surgeon's liability should be prevented or affirmed on policy grounds. A 3:2 majority of judges concluded that the patient should succeed (pp 142-146, 161-163, 163-166)..$^{18}$

In justifying liability, Lord Steyn's reasoning shows the particular emphasis that was placed on the principle of autonomy and its relevance to the purpose of the duty to disclose:

$[\mathrm{N}]$ ot all rights are equally important. But a patient's right to an appropriate warning from a surgeon when faced with surgery ought normatively to be regarded as an important right which must be given effective protection whenever possible... A rule requiring a doctor to abstain from performing an operation without the informed consent of a patient serves two purposes. It tends to avoid the occurrence of the particular physical injury the risk of which a patient is not prepared to accept. It also ensures that due respect is

\footnotetext{
iii It should be noted that in determining causation in Chester, issues of factual and legal causation tended to be conflated by the House of Lords.
} 
given to the autonomy and dignity of each patient (emphasis added) (p 144). ${ }^{18}$

Despite noting that the duty's purpose was, in part and similarly to Wallace, to protect patients from consenting to procedures carrying unacceptable risks, the approach to causation of Lords Hope and Walker (pp 162-163) ${ }^{18}$ was, like that of Lord Steyn, primarily concerned with protecting the patient's right to information: a central aspect of autonomous decision making. Accordingly, their Lordships, in holding the surgeon liable, based their conclusion on the violation of patient autonomy created by the failure to disclose, in the sense that a decision had been made absent relevant information. While criticised by some, ${ }^{22}$ Devaney $^{23}$ and other commentators ${ }^{5}{ }^{24}$ have likewise observed that the 'primary concern of the majority in [Chester] was to ensure that patient autonomy is respected'. ${ }^{23}$

Lord Hoffmann's dissenting judgement in Chester confined the duty's aim to giving patients 'the opportunity to avoid or reduce [a] risk' (p 147). ${ }^{18}$ As such, his Lordship held that practitioners should not be liable where, despite a warning, surgery would be later performed with the same risk to the patient. Lord Bingham agreed ( $\mathrm{p}$ 141-142). ${ }^{18}$ Although a patient's informed decision making is arguably only minimally impacted by the non-disclosure of a risk which, if warned of, would have been accepted by virtue of continuance with a procedure, Lord Hoffmann's decision in Chester does initially appear to de-emphasise the protection of autonomous decision making in non-disclosure cases generally when compared with the majority. Nevertheless, his Lordship's judgement may, in fact, promote autonomy rights more directly by moving away from the requirement to show tangible harm. First, it has been argued that Lord Hoffmann redefined the harm compensated from physical damage to increased 'exposure to risk'. ${ }^{25}$ Second, although litigation costs, by making the law an unsuitable vehicle to distribute the solatium payable, may favour statutory address or compensation, ${ }^{22}$ his Lordship recognised that 'a modest solatium' to vindicate 'the patient's right to choose' may be available (p 147). ${ }^{18}$ Although not ultimately awarded in Chester, similar sums had previously been ordered to protect autonomy interests. ${ }^{26}$

This underlying rationale for the duty of disclosure is now further entrenched by Montgomery. ${ }^{11} 27$ Although restrained in their actual use of the word 'autonomy', 5 Lords Kerr and Reed still emphasise the centrality of patient rights by stating that the practitioner's duty to disclose material information is 'the counterpart of the patient's entitlement to decide whether or not to incur [a] risk' (para 82). ${ }^{1}$ Lady Hale however makes it clear that the law's purpose is to directly prioritise informed and autonomous decision making: 'the interest which the law of negligence protects is a person's interest in their own physical and psychiatric integrity, an important feature of which is their autonomy, their freedom to decide...' (para 108). ${ }^{1}$

In contrast to the position in Australia post-Wallace, the position under English negligence law following Chester and Montgomery therefore arguably affords a much greater level of protection to the notion of autonomy. The UK's Human Rights Act 1998 also provides impetus for securing individual self-determination in that jurisdiction (para 80). ${ }^{1}$ For this reason, we form the view that causation principles are less likely to be used by courts as a control mechanism to limit future liability under English negligence law.

Essentially, the claimant's assertion in Wallace was that the surgeon should be liable because had they disclosed all material risks, the patient would have made an autonomous decision to refuse the procedure, thereby avoiding harm (the neurapraxia) ${ }^{24} 28$ However, the Australian High Court refused to prioritise autonomy in that way. As noted above, the Court instead concluded that the question of whether a patient is willing to accept a risk that eventuates, takes precedence over the notion of their knowledge of that risk for the purpose of autonomous decision making. However, Wheat ${ }^{24}$ and case law ${ }^{29}$ note that the ruling in Chester effectively results in the position where a violation of a patient's right to autonomy per se provides grounds for recovery. Accordingly, Wallace may have been decided differently under English negligence law. This is because Chester supports a causation finding-and thus an award of damages-whenever due to the non-postponement or non-avoidance of surgery, a patient suffers harm relating to 'the very risk' about which an absent warning should have been given (pp 144, 163-166). ${ }^{18}$ This position was not precluded by Montgomery (paras $37-38,105) .{ }^{1}$ It was also open to the Supreme Court to exclude liability by applying the persuasive authority of Wallace. The lower courts, in deciding factual causation, had already held that, had the risk to the child of brachial plexus injury and cerebral palsy been known, Mrs Montgomery would still have delivered vaginally given: the minimal risk of an adverse outcome; the risks of caesarean section ${ }^{12}$; and her degree of faith in the obstetrician (paras 264-267, 43-47). ${ }^{19}$ Accordingly, it might have been argued that Montgomery also involved the occurrence of particular physical injury, the risk of which was not unacceptable to the patient.

A final point of significance, in terms of the duty of disclosure under English negligence law, is that in addition to the material risks of the treatment proposed, healthcare providers are specifically obliged to disclose alternative treatments or interventions. This requirement was confirmed in Montgomery (paras 87, 90, 109). ${ }^{1}$ The provision of such information has also been justified $^{30}$ by reason that a consideration of alternatives and their comparative risks and benefits is necessary in order for a patient to reach a balanced and informed judgement when consenting to treatment proposed. The duty to fully advise of a material risk may also not be discharged unless a patient is apprised of other available procedures carrying no or fewer risks; in Montgomery, caesarean section was allegedly ${ }^{12}$ such an option. Nevertheless, although a possible connection between the duty of disclosure and 'alternative treatment promising greater benefit' was referenced by Gaudron J in Rogers ( $p$ 494), ${ }^{8}$ for Australia, the position is less clear. Certainly, while a duty to inform of the relative risks of alternative treatment has been mentioned in lower courts, ${ }^{31}$ the duty formulated by the High Court majority in Rogers was confined to material risks of the treatment recommended ( $p$ 490). ${ }^{8}$ Also, unlike Montgomery, ${ }^{5}$ it did not on its face extend to a potentially standalone duty to explain all reasonable variant treatments.

An appreciation of this explicit additional component to the healthcare professional's duty, by comparison with Australia, adds further weight to the view that English negligence law concerning disclosure is more focused on furthering autonomous and fully informed decision making.

\section{CONCLUSION}

The UK Supreme Court decision in Montgomery is significant in terms of reframing the duty to disclose information to enable informed consent. Similar to the Australian position, the materiality of risk-from the patient's perspective-is now a key consideration when determining a breach of this duty. Although there is also now the potential for causation rules to be revisited in-depth and be relied on in future cases to limit the scope of 
liability for non-disclosure of material information, in embracing the more patient-centred approach, English jurisprudence has placed the non-violation of patient autonomy squarely at the centre of a healthcare provider's duty. Furthermore, when compared with Australia, Chester and Montgomery appear to give much stronger force to this underlying principle. As discussed, this is likely to be a factor of significance in terms of the application of causation principles where policy-based considerations relevant to causation are intended to reflect the purpose of the duty itself. It is for this reason that we form the view that English negligence law is unlikely to follow the approach to causation exhibited by the Australian High Court in Wallace, as this would signal a stark retreat from its own very recent pronouncement that champions the significance of patient autonomy in modern medical decision making.

Acknowledgements The authors would like to thank, for their feedback and helpful comments, this journal's two anonymous reviewers and José Miola, Professor of Medical Law, University of Leicester, who read an earlier draft of this paper.

Contributors Both authors have contributed to the research undertaken for the writing of this paper, as well as the reasoning, analysis and arguments.

Funding This research received no specific grant from any funding agency in the public, commercial or not-for-profit sectors.

Competing interests None declared.

Patient consent Not required.

Provenance and peer review Not commissioned; externally peer reviewed.

(c) Article author(s) (or their employer(s) unless otherwise stated in the text of the article) 2018. All rights reserved. No commercial use is permitted unless otherwise expressly granted.

\section{REFERENCES}

1 Montgomery v Lanarkshire Health Board [2015] AC 1430 (Montgomery).

2 Farrell AM, Brazier M. Not so new directions in the law of consent? Examining Montgomery v Lanarkshire Health Board. J Med Ethics 2016;42:85-8.

3 Sidaway v Board of Governors of the Bethlem Royal Hospital and Others [1985] AC 871 (Sidaway).

4 Bolam v Friern Barnet Hospital Management Committee [1957] 2 All ER 118.

5 Heywood R. R.I.P. Sidaway: Patient-oriented disclosure - a standard worth waiting for? Med Law Rev 2015;23:455-66.

6 Pearce v United Bristol Healthcare NHS Trust [1999] ECC 167, 174 (Lord Woolf MR).

7 General Medical Council. Seeking patients' consent: The ethical considerations, 1998. http://www.patients_consent_The_ethical_considerations.pdf_25417085.pdf;
General Medical Council. Consent: Patients and doctors making decisions together, 2008. http://www.guidance/consent_guidance_index.asp

8 Rogers v Whitaker (1992) 175 CLR 479 (Rogers).

9 Webster v Burton Hospitals NHS Foundation Trust [2017] EWCA Civ 62.

10 Edozien L. UK law on consent finally embraces the prudent patient standard: But it will take much more to change clinical practice. BMJ 2015;350:h2877.

11 Herring J, Fulford K, Dunn M, et al. Elbow Room for Best Practice? Montgomery, patients' values, and balanced decision-making in person-centred clinical care. Med Law Rev 2017;25(4):582-603.

12 Montgomery J, Montgomery E. Montgomery on informed consent: An inexpert decision? J Med Ethics 2016;42:89-94.

13 Miola J. On the materiality of risk: Paper tigers and panaceas. Med Law Rev 2009;17:76-108.

14 Addison T. Negligent failure to inform: Developments in the law since Rogers $v$ Whitaker. Torts Law Journal 2003:11:165-95.

15 Australian Institute of Health and Welfare. Australia's medical indemnity claims 201213, 2014:60-1, 76. Presents data on public and private sector medical indemnity claims from alleged negligence in the provision of health care services. http://www. health.gov.au/internet/main/publishing.nsf/Content/health-medicalindemnity-pubs. htm. (accessed 12 Jan 2018).

16 NHS Litigation Authority. Report and accounts 2014/15, 2015:29. http://www.nhsla. com/AboutUs/Pages/AnnualReport.aspx. (accessed 12 Jan 2018).

17 Wallace v Kam (2013) 250 CLR 375 (Wallace).

18 Chester v Afshar [2005] 1 AC 134 (Chester).

19 NM v Lanarkshire Health Board [2010] CSOH 104; [2013] CSIH 3.

20 Chappel v Hart (1998) 195 CLR 232.

21 Banque Bruxelles Lambert SA v Eagle Star Insurance Co Ltd [1997] AC 191, 212-4 (Lord Hoffmann).

22 Clark T, Nolan D. A Critique of Chester v Afshar. Oxford Journal of Legal Studies 2014;1-34.

23 Devaney S. Autonomy rules OK. Med Law Rev 2005;13:102-7.

24 Wheat K. Progress of the prudent patient: Consent after Chester v Afshar. Anaesthesia 2005;60:217-9.

25 Jones M, Dugdale A, Simpson M, eds. Clerk and Lindsell on torts. London, UK: Sweet and Maxwell, 2014:68-9.

26 Rees v Darlington Memorial Hospital NHS Trust [2004] 1 AC 309, 317 (Lord Bingham), 319 (Lord Nicholls), 349-50 (Lord Millett), 356 (Lord Scott), applying McFarlane v Tayside Health Board [2000] 2 AC 59, 114 (Lord Millett). Awarded damages, in a negligent sterilisation case, for loss of personal autonomy (the freedom to limit family size).

27 Hobson C. No(,) more Bolam please: Montgomery v Lanarkshire Health Board. Modern Law Review 2016;79:488-503.

28 High Court of Australia, Ian Wallace, 'Appellant's Amended Submissions', Submission in Wallace v Kam, S307 of 2012, 1 November 2012, [4], [41].

29 Jones v Royal Devon and Exeter NHS Foundation Trust (Unreported, Exeter County Court, Recorder Blunt QC, 22 September 2015) [68]-[72]. See also Correia v University Hospital of North Staffordshire NHS Trust [2017] Med LR 292, 295-7 (Simon LJ).

30 Birch v University College London Hospital NHS Foundation Trust [2008] EWHC 2237, [71]-[79] (Cranston J).

31 KL v Farnsworth [2002] NSWSC 382, [135] (Simpson J); F v R (1983) 33 SASR 189, 196 (King CJ). 